\title{
Synthesis of three-arm block copolymer poly(lactic-co-glycolic acid)-poly(ethylene glycol) with oxalyl chloride and its application in hydrophobic drug delivery
}

\author{
This article was published in the following Dove Press journal: \\ International Journal of Nanomedicine \\ 15 November 2016 \\ Number of times this article has been viewed
}

\section{Xiaowei Zhu* \\ Chao Liu* \\ Jianwei Duan \\ Xiaoyu Liang \\ Xuanling Li \\ Hongfan Sun \\ Deling Kong \\ jing Yang}

Tianjin Key Laboratory of Biomaterial Research, Institute of Biomedical Engineering, Chinese Academy of Medical Science and Peking Union Medical College, Tianjin, People's

Republic of China

*These authors contributed equally to this work
Correspondence: Jing Yang

Tianjin Key Laboratory of Biomaterial Research, Institute of Biomedical Engineering, Chinese Academy of Medical Science and Peking Union Medical College, 236 Baidi Road, Nankai, Tianjin 300192, People's

Republic of China

Tel +86228789 0153

Fax +86 2287890153

Email yangjing37@hotmail.com
Purpose: Synthesis of star-shaped block copolymer with oxalyl chloride and preparation of micelles to assess the prospect for drug-carrier applications.

Materials and methods: Three-arm star block copolymers of poly(lactic-co-glycolic acid) (3S-PLGA)-polyethylene glycol (PEG) were synthesized by ring-opening polymerization, then PEG as the hydrophilic block was linked to the terminal hydroxyl of 3S-PLGA with oxalyl chloride. Fourier-transform infrared (FT-IR) spectroscopy, gel-permeation chromatography (GPC), hydrogen nuclear magnetic resonance ( $\left.{ }^{1} \mathrm{H}-\mathrm{NMR}\right)$ spectra, and differential scanning calorimetry were employed to identify the structure and properties of 3S-PLGA-PEG. Rapamycin (RPM)-loaded micelles were prepared by solvent evaporation, and pyrene was used as the fluorescence probe to detect the critical micelle concentration of the copolymer. The particle size, distribution, and $\zeta$-potential of the micelles were determined by dynamic light scattering, and the morphology of the RPM-loaded micelles was analyzed by transmission electron microscopy. High-performance liquid chromatography was conducted to analyze encapsulation efficiency and drug-loading capacity, as well as the release behavior of RPM-loaded micelles. The biocompatibility of material and the cytostatic effect of RPM-loaded micelles were investigated by Cell Counting Kit 8 assay.

Results: FT-IR, GPC, and ${ }^{1} \mathrm{H}-\mathrm{NMR}$ suggested that $3 \mathrm{~S}-\mathrm{PLGA}-\mathrm{PEG}$ was successfully synthesized. The RPM-loaded micelles prepared with the 3S-PLGA-PEG possessed good properties. The micelles had good average diameter and encapsulation efficiency. For in vitro release, RPM was released slowly from 3S-PLGA-PEG micelles, showing that 3S-PLGA-PEG-RPM exhibited a better and longer antiproliferative effect than free RPM.

Conclusion: In this study, we first used oxalyl chloride as the linker to synthesize 3S-PLGAPEG successfully, and compared with reported literature, this method shortened the reaction procedure and improved the reaction yield. The micelles prepared with this material proved suitable for drug-carrier application.

Keywords: block copolymer, RPM, micelles, cytostatic effect

\section{Introduction}

Dissolution is an essential physicochemical property that plays a vital role in the bioavailability of drugs. It is estimated that $40 \%$ or more of new chemical entities are poorly water-soluble and thereby suffer from low bioavailability or erratic absorption. ${ }^{1}$ Formulations of these substances pose a significant challenge for the development of viable dosage forms during early stages of drug development. 
The drug-delivery carrier is an important factor in the field of nanomedicine, and is an ideal solution for the solubility of hydrophobic drugs, the global trend focusing on the design of highly sophisticated drug-delivery systems with specific functions to increase drug-therapy efficacy over the past few years. ${ }^{2}$ The applications of amphiphilic polymers in drugdelivery systems are extensive, eg, micelles, ${ }^{3-5}$ vesicles, ${ }^{6}$ microspheres, ${ }^{7}$ and nanoparticles. ${ }^{8}$ Research on micelles as drug carriers is growing rapidly, on account of their special core-shell structure. Amphiphilic block copolymers, which possess a hydrophilic head and a hydrophobic tail, selfassemble into micelles in aqueous solution, and the hydrophobic center is achieved in this process. ${ }^{3,9}$ These could not only be used as the delivery material of hydrophobic drugs ${ }^{10}$ but could also be used in the delivery of hydrophilic drugs ${ }^{11,12}$ and peptides, ${ }^{13}$ which significantly enhance the permeability of various drugs and prolong retention.

All kinds of aliphatic polyesters, such as poly(L-lactic acid) (PLA), ${ }^{14,15}$ poly( $\varepsilon$-caprolactone), ${ }^{13,16}$ and poly(lacticco-glycolic acid) (PLGA), ${ }^{17}$ have been linked with a hydrophilic polyethylene glycol (PEG) segment to yield the amphiphilic copolymer structure. ${ }^{18}$ In 1994 , the effect on pharmacokinetics of PLGA microparticles externally coated with PEG was first described. ${ }^{19}$ PLGA-PEG attracts much attention, due to its different properties when compared with other constituting polymers. PEG linked to PLGA not only significantly improves the hydrophilicity of PLGA but also greatly prolongs the cycle of drugs in the body. ${ }^{20}$ Also, PEG has good solubility in water and high solubility in most organic solvents. These features make it easier to react with PLGA in organic solvent, which greatly reduces the difficulty of the reaction.

Dicyclohexylcarbodiimide (DCC) and $N$-hydroxysuccinimide (NHS) are normally used in esterification reactions. PLGA-PEG is normally synthesized with DCC/NHS reaction, ${ }^{17,21}$ though other coupling agents such as 1-ethyl3-(3-dimethylaminopropyl) or 1,1'-carbonyldiimidazole are used instead of DCC to achieve the same results. ${ }^{22}$ However, these reactions need carboxylation of PLGA and amination of PEG, which extend the reaction steps and decrease productivity. In our study, we first used oxalyl chloride as the linker to synthesize PLGA-PEG, and compared with the literature reported, this method shortened the reaction procedure and improved the reaction yield. Oxalyl chloride with two acyl chloride groups in the structure was a strong acylation reagent and reacted easily with polymers with hydroxyl $(\mathrm{OH})$ groups. ${ }^{23}$ Then, polymers with terminal acyl chloride groups were obtained while excess oxalyl chloride existed. These acyl chloride-capped polymers reacted with other polymers with $\mathrm{OH}$ groups under alkaline conditions, and block polymers were synthesized in this process. ${ }^{24}$

Nowadays, there are various polymer structures, eg, grafts, ${ }^{25}$ brushes, ${ }^{26}$ stars, ${ }^{17}$ dendrites, and macromolecules, ${ }^{27}$ attracting much attention. Polymers with multiarm structure greatly enrich the treasury of drug-delivery carriers and also increase the modifiable functional end groups. Compared with those of linear structure, star-shaped polymers have advantages of highly ordered branched structure, exact molecular weight, abundant functional groups, low viscosity, and high solubility, which make them extensively used in biology and drug-delivery. ${ }^{9,28,29}$ The branched chains extend all around star-polymer materials, which can be used with drug-loaded balls with narrow dispersion and improve drugcarrier stability in the circulation, due to the tight circle and the multiple modified sites of the polymer. ${ }^{30}$

Therefore, as shown in Figure 1, three-arm star block copolymers (3S-PLGA-PEG) were synthesized with oxalyl chloride, and the biocompatibility of 3S-PLGA-PEG was observed. Then, rapamycin (RPM) was used as the model drug to evaluate the ability of the copolymer as the hydrophobic drug carrier.

\section{Materials and methods Materials}

D,L-Lactide (DLA) and GA were procured from Glaco Ltd (Beijing, People's Republic of China). Stannous octoate $\left(\mathrm{SnOct}_{2}\right)$ was bought from Sigma-Aldrich (St Louis, MO, USA). PEG (number-average molecular weight $\left.=4,000 \mathrm{~g} \cdot \mathrm{mol}^{-1}\right)$, propanetriol, and oxalyl chloride were obtained from Guangfu Fine Chemical Research Institute (Tianjin, People's Republic of China). Calcium hydride, pyrene, tetrahydrofuran, dichloromethane, $N, N$-dimethylformamide, methanol, and acetone were bought from Jiangtian Chemical Technology Co Ltd (Tianjin, People's Republic of China). RPM was purchased from North China Pharmaceutical (Shijiazhuang, People's Republic of China). Acetonitrile and methanol (high-performance liquid chromatography [HPLC] grade), used as the mobile phase of HPLC, were purchased from Concord Technology Co Ltd (Tianjin, People's Republic of China). Phosphate-buffered saline (PBS) was purchased from Shijiazhuang Biotechnology Co Ltd (Shijiazhuang, People's Republic of China), Dulbecco's Modified Eagle's Medium (DMEM)/F-12 (HyClone) from GE Healthcare (Little Chalfont, UK), and fetal bovine serum from Solarbio Science and Technology Co Ltd (Beijing, People's Republic of China). Dichloromethane was distilled over calcium hydride. Other reagents were used as received. 


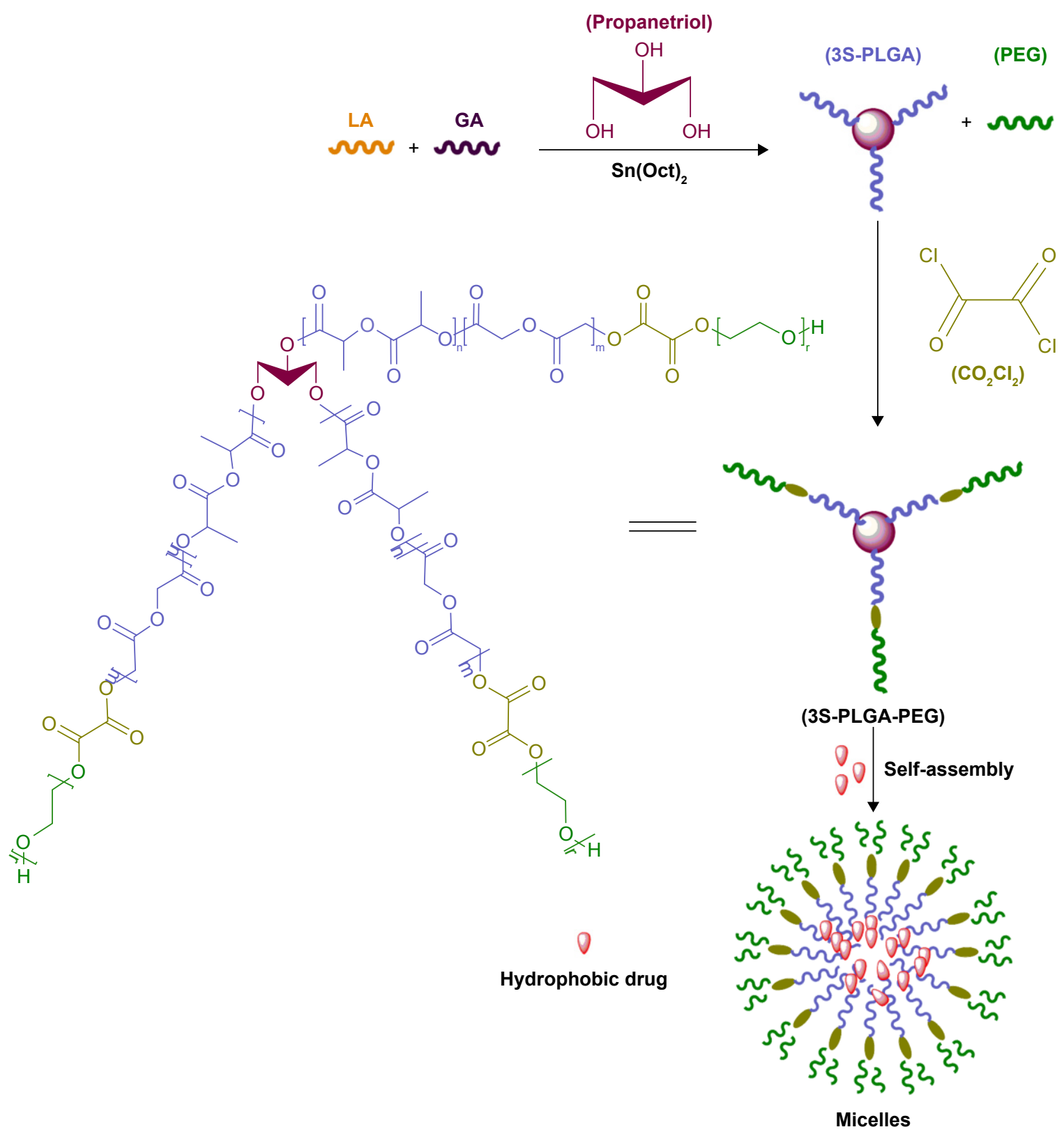

Figure I Design of the entire study: the copolymer was synthesized by two simple steps. Firstly, propanetriol was employed as the initiator for the synthesis of 3S-PLGA by ring-opening polymerization. Secondly, 3S-PLGA was linked with PEG by acylation reaction, in which oxalyl chloride was used as the linkage. Then, the hydrophobic drug was incorporated into the hydrophobic core to evaluate the ability of this copolymer as the drug-delivery carrier.

Abbreviations: 3S-PLGA, three-arm star block poly(lactic-co-glycolic acid); PEG, polyethylene glycol; LA, lactic acid; GA, glycolic acid.

\section{Synthesis of 3S-PLGA}

Firstly, SnOct ${ }_{2}$ was dissolved in dichloromethane $\left(\mathrm{CH}_{2} \mathrm{Cl}_{2}\right)$ with a concentration of $7.64 \times 10^{-3} \mathrm{~mol} \cdot \mathrm{L}^{-1}$. A mixture of dried DLA (4.32 g, $30 \mathrm{mmol}), \mathrm{GA}(1.16 \mathrm{~g}, 10 \mathrm{mmol})$, SnOct $_{2}$ solution ( $0.523 \mathrm{~mL}, 0.004 \mathrm{mmol})$, and propanetriol (18.4 mg, $0.2 \mathrm{mmol}$ ) was added into a clean, dry polymerization flask, then vacuum pumping for 10 minutes and argon filling for 1 minute were undertaken alternately three times to remove the oxygen and $\mathrm{CH}_{2} \mathrm{Cl}_{2}$ in the flask. Following this, another 30 minutes of degassing was required. Polymerization was carried out in a vacuum oven at $160^{\circ} \mathrm{C}$ for 8 hours. After cooling to room temperature, the crude product was dissolved in $\mathrm{CH}_{2} \mathrm{Cl}_{2}$ and purified by precipitating in cooled methanol three times. Finally, 3S-PLGA was dried at room temperature in vacuum until constant weight (4.80 g, 87.5\%).

\section{Synthesis of 3S-PLGA-PEG}

Oxalyl chloride ( $0.330 \mathrm{~g}, 2.6 \mathrm{mmol})$ was dissolved in $1 \mathrm{~mL}$ anhydrous $\mathrm{CH}_{2} \mathrm{Cl}_{2}$ in a $50 \mathrm{~mL}$ flask, and an anhydrous $\mathrm{CH}_{2} \mathrm{Cl}_{2}$ solution of PEG (1.30 g, $\left.0.325 \mathrm{mmol}\right)$ was added dropwise into the flask under stirring at $4{ }^{\circ} \mathrm{C}$. After reaction for 3 hours, $\mathrm{CH}_{2} \mathrm{Cl}_{2}$ was removed by evaporation. The residue 
was redissolved and reevaporated three times to remove oxalyl chloride thoroughly. Then, the residue was dissolved in $10 \mathrm{~mL}$ anhydrous $\mathrm{CH}_{2} \mathrm{Cl}_{2}$ in a $50 \mathrm{~mL}$ flask, and $15 \mathrm{~mL}$ anhydrous $\mathrm{CH}_{2} \mathrm{Cl}_{2}$ containing $3 \mathrm{~S}-\mathrm{PLGA}(1 \mathrm{~g}, 0.036 \mathrm{mmol})$ and tetraethylammonium $(0.011 \mathrm{~g}, 0.113 \mathrm{mmol})$ were added dropwise into a flask under stirring at room temperature. The mixture was further stirred for about 48 hours at room temperature under nitrogen atmosphere. The organic mixture was washed three times with $1 \mathrm{M} \mathrm{HCl}$ and dried over $\mathrm{MgSO}_{4}$ and $\mathrm{NaHCO}_{3}$. The drying agent was removed by filtration. The filtered solution was precipitated in cool diethyl ether three times and washed by cool methanol to remove the redundant PEG. The product was dried at $40^{\circ} \mathrm{C}$ in vacuum until constant weight $(0.94 \mathrm{~g}, 65 \%)$.

\section{Characterization of 3S-PLGA-PEG}

The structure and composition of the copolymer were analyzed by ${ }^{1} \mathrm{H}$-nuclear magnetic resonance (NMR) spectroscopy (400 MHz; Varian Inc, Palo Alto, CA, USA) with $\mathrm{CDCl}_{3}$ as the solvent and tetramethylsilane as the internal reference with a chemical shift of 0 ppm. Infrared spectra were recorded on a Nicolet Nexus 470-ESP Fourier-transform infrared (FT-IR) spectrometer (Thermo Fisher Scientific, Waltham, MA, USA). Molecular weight and molecular weight distribution of the copolymer were measured by gelpermeation chromatography (GPC) using a Hitachi L-2490 differential refraction detector and two PLgel $7.5 \times 300 \mathrm{~mm}$, $10 \mathrm{~mm}$ particle columns (Agilent Technologies, Santa Clara, CA, USA). Polymethyl methacrylate was used as the standard. The glass-transition temperature $\left(\mathrm{T}_{\mathrm{g}}\right)$ of the copolymer was investigated by differential scanning calorimetry using a Q2000 calorimeter (TA Instruments, New Castle, DE, USA). Samples of about $5 \mathrm{mg}$ were heated from $0^{\circ} \mathrm{C}$ to $100^{\circ} \mathrm{C}$ in a nitrogen atmosphere $(50 \mathrm{~mL} / \mathrm{min})$ at a rate of $5^{\circ} \mathrm{C} / \mathrm{min}$.

\section{Biocompatibility of 3S-PLGA-PEG in vitro}

The biocompatibility of 3S-PLGA-PEG with human aortic vascular smooth-muscle cells (HA-VSMCs; T/G; American Type Culture Collection, Manassas, VA, USA) was assessed by Cell Counting Kit (CCK)-8 assay. Cells were incubated at $37^{\circ} \mathrm{C}$ in a $5 \%(\mathrm{v} / \mathrm{v})$ carbon dioxide-atmosphere incubator in DMEM/F-12 with $10 \%$ fetal bovine serum and $1 \%$ penicillin-streptomycin.

Cells were seeded in 96-well plates at a density of 5,000 cells/well containing $200 \mu \mathrm{L}$ of culture medium and incubated for 24 hours to reach $90 \%$ confluence. Cells were treated with various amounts of micelles $(10,50,100 \mu \mathrm{g} / \mathrm{mL})$ and incubated for 24 hours. Following this, the medium was removed, then $200 \mu \mathrm{L}$ of mixture medium (DMEM/F-12 with $10 \%$ fetal bovine serum/CCK-8, 9/1, v/v) was added to each well, and the plates were incubated for 4 hours. Optical density (OD) was measured at $450 \mathrm{~nm}$ with a Varioskan Flash microplate reader (Thermo Fisher Scientific). Relative cell viability was calculated as:

$$
\text { Cell viability }(\%)=\frac{O D_{\text {treat }}-\mathrm{OD}_{\text {blank }}}{O D_{\text {control }}-\mathrm{OD}_{\text {blank }}} \times 100 \%
$$

where $\mathrm{OD}_{\text {treat }}$ and $\mathrm{OD}_{\text {control }}$ were the absorbance of the treated and control cells, respectively, and $\mathrm{OD}_{\text {blank }}$ the absorbance of the medium material that was used for zero adjustment. The results are represented as mean \pm standard deviation $(\mathrm{SD} ; \mathrm{n}=3){ }^{8}$

In order to investigate the biocompatibility of the materials further, mouse macrophage (RAW264.7) cells were cocultured with the materials, and the cytokines released from RAW264.7 cells were determined by enzyme-linked immunosorbent assay (ELISA). Cells were incubated at $37^{\circ} \mathrm{C}$ in a $5 \%(\mathrm{v} / \mathrm{v})$ carbon dioxide-atmosphere incubator in Roswell Park Memorial Institute 1640 medium with 10\% fetal bovine serum and $1 \%$ penicillin-streptomycin.

Cells were seeded in 24-well plates at a density of $5 \times 10^{5}$ cells/well containing $1 \mathrm{~mL}$ culture medium and incubated for 24 hours. Cells were treated with various amounts of micelles $(0.01,0.1,1,10,100 \mu \mathrm{g} / \mathrm{mL})$ and incubated for 48 hours. Following this, cell supernatants were analyzed for the presence of cytokines, ie, interleukin-6 (IL-6) and tumor necrosis factor alpha (TNF $\alpha$ ). Lipopolysaccharide was used as the positive control, and cells without any treatment were considered the negative control. ${ }^{31}$

\section{Preparation of RPM-loaded 3S-PLGA- PEG micelles}

As shown in Figure 2, RPM-loaded 3S-PLGA-PEG micelle (3S-PLGA-PEG-RPM) were prepared by solvent evaporation. 3S-PLGA-PEG (100 mg) and $30 \mathrm{mg}$ of RPM were weighted accurately and dissolved in $4 \mathrm{~mL}$ acetone. The mixture solution was added dropwise slowly into $20 \mathrm{~mL}$ distilled water under stirring, then further stirring overnight at room temperature till the organic solvent was evaporated completely. The micelles were washed three times by distilled water and ultracentrifugation at $23,000 \mathrm{rpm}, 4^{\circ} \mathrm{C}$ for 30 minutes. The micelles were harvested and resuspended in $4 \mathrm{~mL} 20 \%$ PEG aqueous solution, while the supernatant was collected and used for quantification of encapsulation efficiency (EE). Finally, the dispersed solution was 


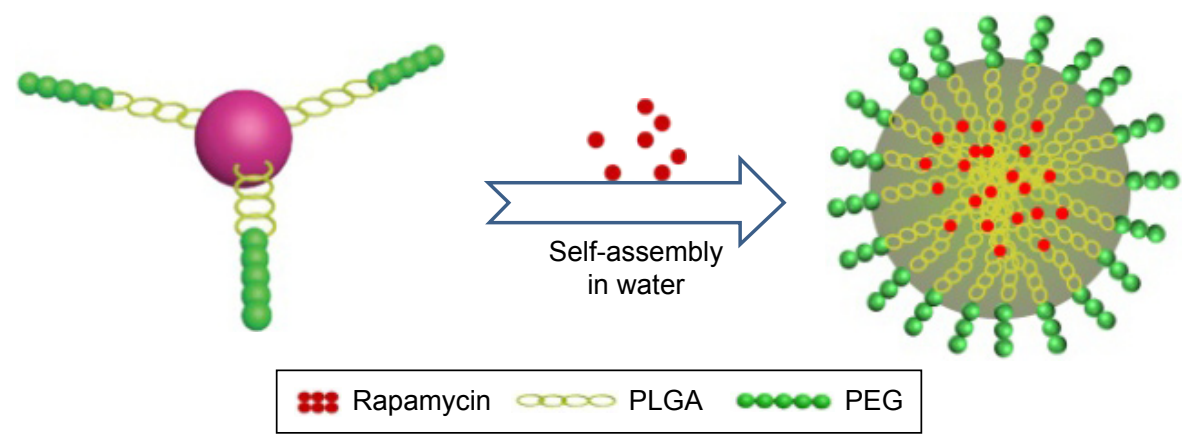

Figure 2 Schematic diagram of rapamycin-loaded three-arm star-shaped PLGA-PEG micelles. Micelles were formed in aqueous solution through self-assembly technology; rapamycin was incorporated in the hydrophilic center.

Abbreviations: PLGA, poly(lactic-co-glycolic acid); PEG, polyethylene glycol.

lyophilized. Micelles with no drugs were prepared with the same method.

\section{Characterization of micelles \\ Critical micelle-concentration determination of 3S-PLGA-PEG}

The critical micelle concentration (CMC) of 3S-PLGA-PEG in water was detected with the Varioskan Flash microplate reader, where pyrene was used as the fluorescence probe. Micelles at a concentration of $0.5 \mathrm{mg} / \mathrm{mL}$ were prepared by solvent evaporation. The micelle concentration was diluted from $5 \times 10^{-1} \mathrm{mg} / \mathrm{mL}$ to $5 \times 10^{-7} \mathrm{mg} / \mathrm{mL}$, and pyrene concentration was fixed at $3 \times 10^{-4} \mathrm{mg} / \mathrm{mL}$. After ultrasonication for 20 minutes, micelles were incubated overnight. Fluorescence-excitation spectra were measured at emission wavelength of $394 \mathrm{~nm}$ and a slit width of $3 \mathrm{~nm}$. The ratio of fluorescence intensity at 335 and $338 \mathrm{~nm}$ was obtained through scanning from $290 \mathrm{~nm}$ to $360 \mathrm{~nm}$. The $\mathrm{CMC}$ can be calculated from the curve of $\mathrm{I}_{338} / \mathrm{I}_{335}$ against the logarithm of copolymer concentration.

\section{Size, $\zeta$-potential, morphology, stability, and ability of drug load}

Mean particle size, size distribution, and $\zeta$-potential of the micelles were determined by dynamic light scattering on a Zetasizer Nano ZS (Malvern Instruments, Malvern, UK). All measurements were carried out in triplicate. The average particle size was expressed in mean volume diameter, and reported values are represented as mean $\pm S D(n=3)$. The aqueous micelles were stored at $4{ }^{\circ} \mathrm{C}$ in a static state. Dynamic light scattering was used to measure the mean particle size and distribution every 15 days for 1 month. The results are expressed as mean $\pm \operatorname{SD}(n=3)$.

The morphology of the RPM-loaded micelles was analyzed by transmission electron microscopy (TEM; Tianjin
Research Center of Basic Medical Science). Micelles $(200 \mu \mathrm{g})$ were weighted accurately and dissolved in $1 \mathrm{~mL}$ distilled water. Then, the sample was obtained by placing a drop of fresh prepared micelle suspension onto a copper grid. After being air-dried overnight, the sample was examined by TEM.

Encapsulation efficiency (EE) and drug-loading (DL) capacity were detected by HPLC. RPM-loaded micelles $(5 \mathrm{mg})$ were weighed accurately and dissolved in $1 \mathrm{~mL}$ dichloromethane. After dichloromethane had been completely removed in the fume hood, $1 \mathrm{~mL}$ acetonitrile was added and RPM determined by the established HPLC method. Typically, $20 \mu \mathrm{L}$ samples were injected into a reverse-phase diamond C18 column $(150 \times 4.6 \mathrm{~mm}, 5 \mu \mathrm{m}$; Agilent Technologies $)$ and eluted with mobile phase (acetonitrile:water, 75:25, v:v) at a flow rate of $1 \mathrm{~mL} / \mathrm{min}$. An ultraviolet detector was used to detect RPM at $277 \mathrm{~nm}$. EE\% and DL\% were calculated by equations 1 and 2 . The determinations were carried out in triplicate, and results are expressed as mean $\pm \operatorname{SD}(n=3)$ :

$$
\begin{gathered}
\mathrm{EE} \%=\frac{\text { Mass of total RPM in micelles }}{\text { Mass of RPM theoretical }} \times 100 \% \\
\mathrm{DL} \%=\frac{\text { Mass of RPM in micelle }}{\text { Mass of micelles }} \times 100 \%
\end{gathered}
$$

\section{RPM-release behavior in vitro}

RPM-loaded micelles (5 mg) were weighed accurately and dissolved in $4 \mathrm{~mL}$ PBS (pH 7.4), and shaken at $150 \mathrm{rpm}$ at $37^{\circ} \mathrm{C}$ for 32 days. At the setting time points, $2 \mathrm{~mL}$ of supernatant was taken out after centrifugation and the same volume of PBS was added. The free RPM was extracted by dichloromethane and detected by HPLC. Then, a cumulative release curve of 32 days was drawn according to the standard curve. 


\section{Cytostatic effect analysis in vitro}

Cytostatic assay of 3S-PLGA-PEG-RPM was also undertaken on T/G HA-VSMCs, and cells were incubated under the same protocol as the biocompatibility analysis. Then, cells were treated with different RPM concentrations (the solution was diluted from $10 \mu \mathrm{g} / \mathrm{mL}$ to $0.001 \mu \mathrm{g} / \mathrm{mL}$ ) contained in micelles for regular incubation times (24, 48, 72 hours). Free RPM with the same concentration was the control group. Then, the viability of cells was detected by CCK-8 assay with the same method as in the "Biocompatibility of 3S-PLGA-PEG in vitro" section. Results are expressed as mean $\pm \operatorname{SD}(n=3)$.

\section{Results and discussion Characterization of 3S-PLGA-PEG}

Many methods have been used to synthesize amphiphilic copolymers, which normally divide into two kinds of polymerization. For instance, Hassouna et al developed the plasticized PLA grafting of PEG via reactive extrusion. ${ }^{15}$ In another study, Dong and Feng used MPEG as an initiator to get MPEG-PLA. ${ }^{32}$ Random block copolymers were synthesized by these methods, which modified the end group verbosely. DCC and NHS are always utilized in regular polymerization to achieve PLGA-PEG, which increases the reaction steps and reduces the yield. ${ }^{17}$ In this study, the copolymer was synthesized in two steps. Firstly, propanetriol was employed as the initiator for the synthesis of 3S-PLGA by ring-opening polymerization. Secondly, 3S-PLGA was linked with PEG by acylation reaction, in which oxalyl chloride was used as the linkage. The synthetic route is depicted in Figure 1. In future, PLGA can be linked with amino PEG easily by oxalyl chloride linkage to get the end group-modified amphiphilic copolymer by this method.

The chemical structure of 3S-PLGA-PEG was investigated by ${ }^{1} \mathrm{H}-\mathrm{NMR}$ spectra. As shown in Figure 3A, the synthesis of 3S-PLGA was determined mainly by the appearance of the peaks of a $\left(\delta=1.55 \mathrm{ppm},-\mathrm{CH}_{3}\right.$ in PLGA segments), b ( $\delta=4.82 \mathrm{ppm},-\mathrm{CH}_{2}$ in PLGA segments), and $\mathrm{c}(\delta=5.12,-\mathrm{CH}$ in PLGA segments). Compared with the 3S-PLGA spectrum, the high intensity of peak d ( $\delta=3.62 \mathrm{ppm},-\mathrm{CH}_{2}$ in PEG segments) in the 3S-PLGA-PEG spectrum indicated the existence of the PEG, which proved that 3S-PLGA-PEG had been successfully synthesized.

FT-IR spectrometry was also used to evaluate the chemical structure of the copolymer. As shown in Figure 3B, the characteristic peak of $3 \mathrm{~S}-\mathrm{PLGA}$ at $1,750 \mathrm{~cm}^{-1}$ was attributable to the $\mathrm{C}=\mathrm{O}$ functional group, while the peaks at $2,995 \mathrm{~cm}^{-1}$ and $2,945 \mathrm{~cm}^{-1}$ were due to the stretching vibration of saturated $-\mathrm{CH}$ bond. In the spectrum of 3S-PLGA-PEG, the emerging peaks of $2,879 \mathrm{~cm}^{-1}, 1,092 \mathrm{~cm}^{-1}$, and $842 \mathrm{~cm}^{-1}$ proved the existence of the PEG chain.

Molecular weights and polydispersity were investigated by GPC, as shown in Figure 3C: the peak of 3S-PLGA-PEG appears earlier compared with the peak of 3S-PLGA, which proved that the PEG was favorably linked with 3S-PLGA. Furthermore, the unimodal GPC trace with low polydispersity value demonstrated that the 3S-PLGA-PEG was successfully synthesized.

The thermal properties of 3S-PLGA-PEG were investigated by differential scanning calorimetry. As shown in Figure $3 \mathrm{D}$, the $\mathrm{T}_{\mathrm{g}}$ of the $3 \mathrm{~S}-\mathrm{PLGA}$ was about $50.91^{\circ} \mathrm{C}$, while 3S-PLGA-PEG was $47.5^{\circ} \mathrm{C}$. The results showed that the $\mathrm{T}_{\mathrm{g}}$ of 3S-PLGA-PEG was lower than 3S-PLGA because the existence of PEG can affect the crystalline property of PLGA, which can reduce the $T_{\mathrm{g}}$ of this polymer, ${ }^{33,34}$ and suggested the PEG segment was linked with PLGA.

\section{Biocompatibility of 3S-PLGA-PEG in vitro}

In this study, 3S-PLGA-PEG was used as the drug carrier in micelle form. Therefore, we examined the biocompatibility of blank micelles. The biocompatibility of blank micelles was tested on the T/G HA-VSMCs. The results were analyzed by equation 1 (Materials and methods), and SPSS software was utilized to cope with the data. As shown in Figure 4A, the cell viability of all polymer groups exceeded $90 \%$ compared with the control. The results suggested that the 3S-PLGA-PEG, synthesized by these two simple steps, has good biocompatibility.

There have been many investigators to utilize the in vitro cell-culture model using RAW264.7 cells for the estimation of biocompatibility of polymeric materials intended for human applications by CCK-8 and MTS assay. In this study, the cytokines' (IL- 6 and TNF $\alpha$ ) release in culture supernatant was examined after exposure to 3S-PLGA-PEG for 48 hours. Samples were analyzed by ELISA. IL- 6 and TNF $\alpha$ were the typical inflammatory cytokines. ${ }^{35,36}$ As shown in Figure 4B, there was no significant difference in release of cytokines between micelle groups and the negative-control group, while much cytokine material was detected in the positive group. Results indicated that 3S-PLGA-PEG would not elicit inflammatory responses in RAW264.7 cells in vitro. Therefore, the results of ELISA further suggested that 3S-PLGA-PEG has good biocompatibility.

\section{Characterization of micelles CMC of 3S-PLGA-PEG micelles}

Fluorescence spectroscopy involving pyrene or phenytoin sodium and other similar fluorescent agents is the general 
A
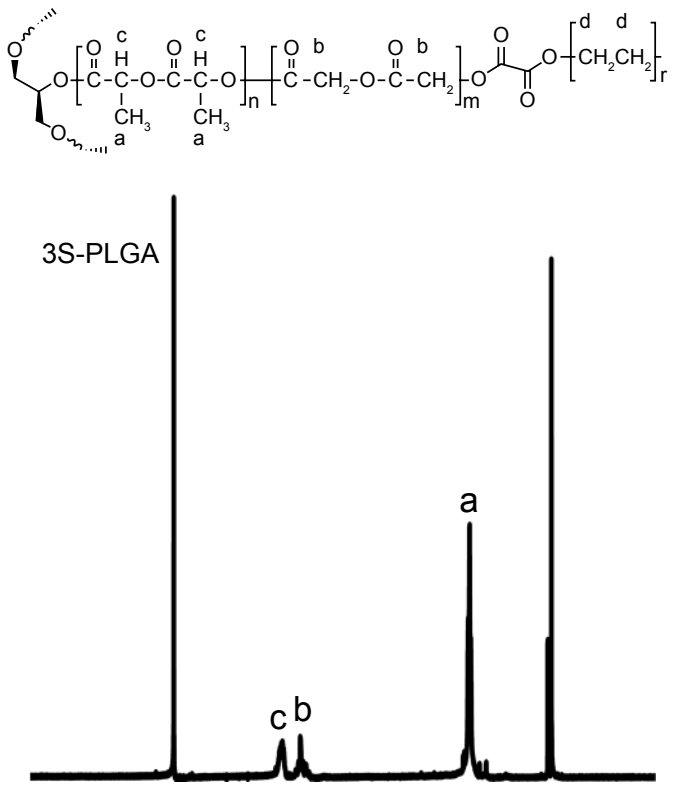

3S-PLGA-PEG

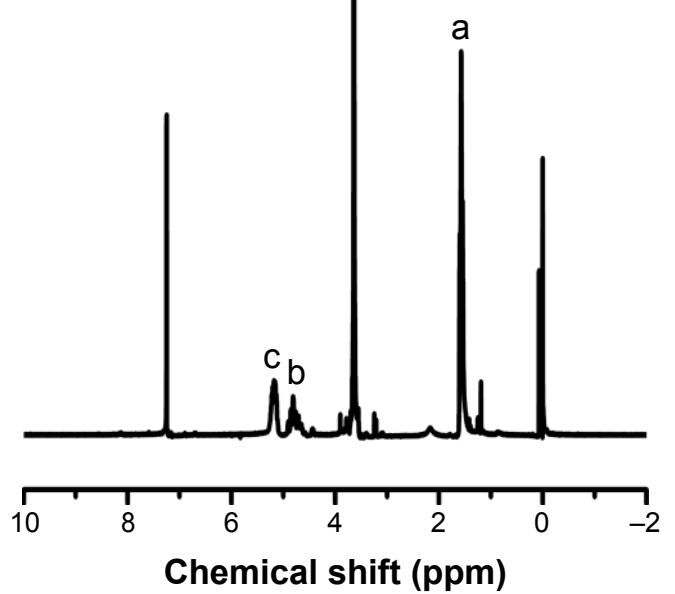

B

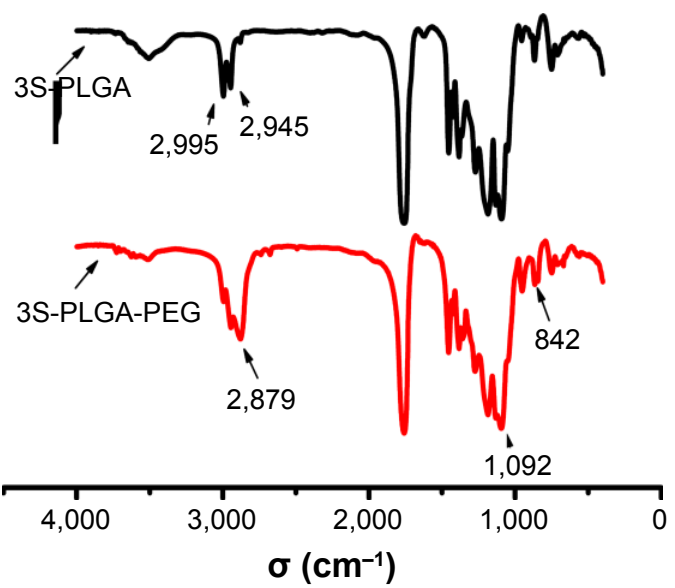

C
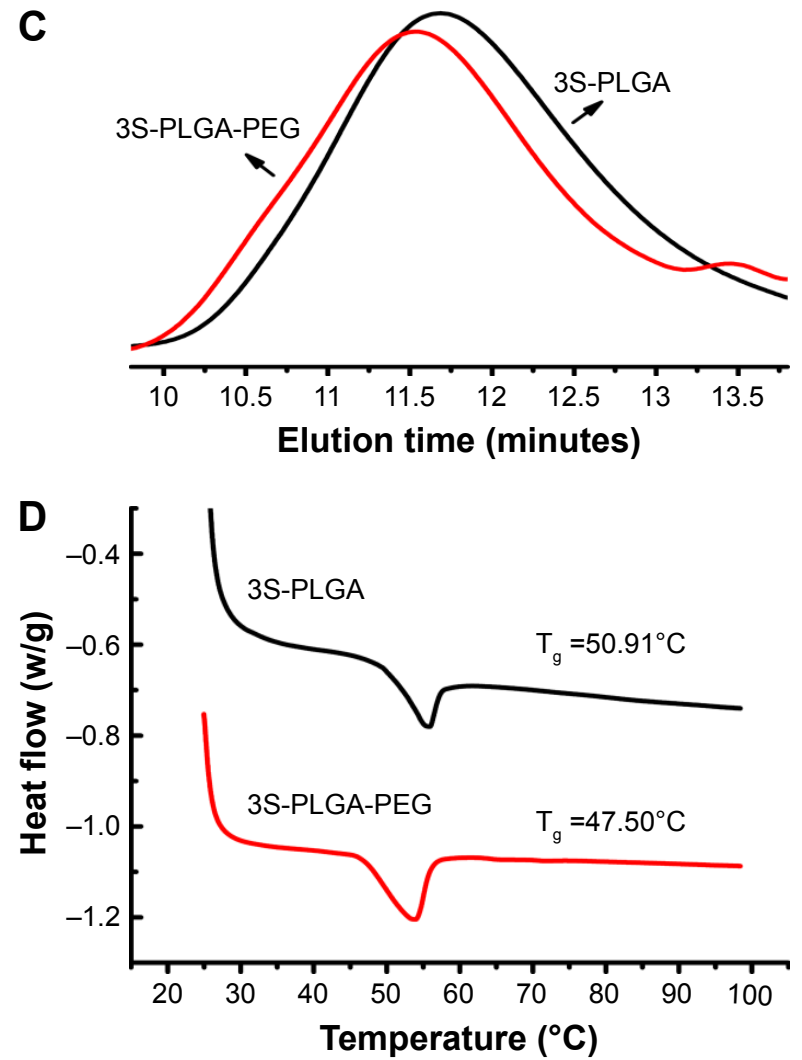

Figure 3 (A) The chemical structure of 3S-PLGA-PEG was investigated by 'H-NMR spectra. 3S-PLGA was mainly determined by the appearance of the peaks of a $\left(\delta=1.55\right.$ ppm, $-\mathrm{CH}_{3}$ in PLGA segments), b ( $\delta=4.82 \mathrm{ppm},-\mathrm{CH}_{2}$ in PLGA segments), and c ( $\delta=5.12 \mathrm{ppm},-\mathrm{CH}$ in PLGA segments). Compared with the $3 \mathrm{~S}-\mathrm{PLGA}$ spectrum, the high intensity of peak $d\left(\delta=3.62 \mathrm{ppm},-\mathrm{CH}_{2}\right.$ in PEG segments) in the 3S-PLGA-PEG spectrum indicated the existence of PEG, which proved that $3 \mathrm{~S}-\mathrm{PLGA}-\mathrm{PEG}$ was successfully synthesized. (B) FT-IR spectrometry: the characteristic peak of $3 S-P L G A$ at I,750 $\mathrm{cm}^{-1}$ was attributable to the C=O functional group, while the peaks at $2,995 \mathrm{~cm}^{-1}$ and $2,945 \mathrm{~cm}^{-1}$ were due to the stretching vibration of a saturated $-\mathrm{CH}$ bond. In the spectrum of $3 S-P L G A-P E G$, the emerging peaks of $2,879 \mathrm{~cm}^{-1}$, I,092 $\mathrm{cm}^{-1}$, and $842 \mathrm{~cm}^{-1}$ proved the existence of the PEG chain. (C) Molecular weights and polydispersity were investigated by GPC: the peak of 3S-PLGA-PEG appeared earlier than the peak of 3S-PLGA, which proved that PEG was favorably linked with 3S-PLGA. (D) The glass transition temperature $\left(\mathrm{T}_{\mathrm{g}}\right)$ of $3 \mathrm{~S}-\mathrm{PLGA}$ was about $50.9 \mathrm{I}^{\circ} \mathrm{C}$, while $3 \mathrm{~S}-\mathrm{PLGA}-\mathrm{PEG}$ was $47.5^{\circ} \mathrm{C}$. The existence of PEG affected the crystalline property of PLGA, which reduced the $T_{g}$ of this polymer.

Abbreviations: 3S-PLGA, three-arm star block poly(lactic-co-glycolic acid); PEG, polyethylene glycol; NMR, nuclear magnetic resonance; FT-IR, Fourier-transform infrared; GPC, gel-permeation chromatography.

method used to determine the CMC of copolymers. Pyrene is frequently used as the fluorescence probe in this measurement, because it is very sensitive to the polarity of the surrounding environment. ${ }^{37}$ With the increase in polymer concentration in aqueous solution, there was a dramatic increase in the fluorescence intensity of pyrene because much more pyrene was incorporated into the hydrophobic core with the change in polarity of the environment. The $\mathrm{I}_{338} / \mathrm{I}_{335}$ value in the excitation spectrum was raised. CMC value was calculated according to the turning point. As shown in Figure 5A, 

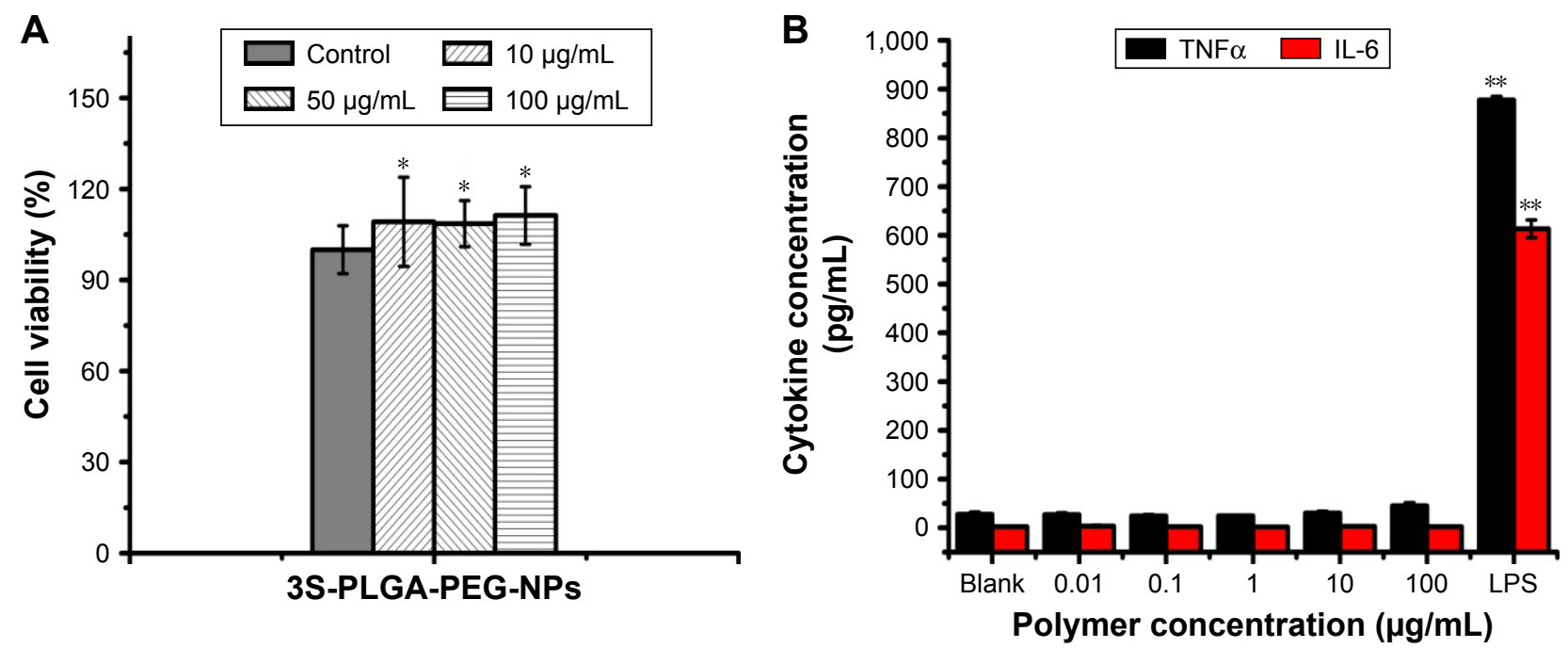

Figure 4 Biocompatibility of blank micelles. $* P<0.05 ; * * P<0.0$ I. (A) Micelles were tested on human aortic vascular smooth-muscle cells (T/G). The results suggested that the three-arm polymers had good biocompatibility. (B) RAW264.7 cells were cocultured with materials, with results indicating that the materials would not elicit an inflammatory response, thus further suggesting 3S-PLGA-PEG had good biocompatibility.

Abbreviations: 3S-PLGA, three-arm star block poly(lactic-co-glycolic acid); PEG, polyethylene glycol; NPs, nanoparticles; LPS, lipopolysaccharide; TNF $\alpha$, tumor necrosis factor alpha; IL, interleukin.

the CMC of $3 \mathrm{~S}-\mathrm{PLGA}-\mathrm{PEG}$ was $7.08 \times 10^{-4} \mathrm{mg} / \mathrm{mL}$, due to the lower content of PEG in the copolymer. ${ }^{38}$ Moreover, this was also probably because the covalent bond character of star-shaped block copolymers with many arms was similar to the micellar state, which facilitated the micellization, ${ }^{17}$ so 3S-PLGA-PEG may be a promising and potent drug carrier because of its ease in use.

\section{Size, $\zeta$-potential, morphology, stability, and drug-loading capacity}

For polymeric micelles, size and surface charge can influence the efficiency and pathway of cellular uptake ${ }^{39,40}$ by affecting the adhesion of the particles and their interactions with cells. ${ }^{41}$ The micelles made in the laboratory exhibited suitable particle size and negative charge. As shown in Figure 5B, blank micelles and RPM-loaded 3S-PLGA-PEG micelles were small, $161.3 \pm 1.6 \mathrm{~nm}$ (polydispersity index $0.157 \pm 0.004$ ) and $166.6 \pm 1.6 \mathrm{~nm}$ (polydispersity index $0.145 \pm 0.012$ ), respectively, they were suited for circulation in blood and resided in tissue. ${ }^{42,43}$ Particle size can be adjusted by the length of the hydrophobic segment chain. ${ }^{44}$ In our design, the content of the hydrophobic chain was much more than the hydrophilic segment, which made it bigger than the general micelles, commonly sized 10-100 nm.

The surface charges of blank and RPM-loaded micelles were $-9.09 \pm 0.55 \mathrm{mV}$ and $-10.27 \pm 0.09 \mathrm{mV}$, respectively, relatively smaller compared with the bigger negative charge of most cell lines. The slight charge difference between particles and cell lines can augment the cellular uptake of nonmacrophages. ${ }^{43}$

As in the TEM in Figure 5C, we found that the obtained micelles appeared similarly spherical and separated from one another. Furthermore, this showed the core-shell structure and formed a crew-cut shape because of the lower hydrophilic chain length than the hydrophobic segment in the copolymer. ${ }^{45}$

For DL of micelles, over $60 \%$ of RPM was incorporated into the micelles of the multiarm copolymer because of the branched structure. ${ }^{46}$ As shown in studies by Chen et $\mathrm{al}^{8}$ and Ma et al, ${ }^{17}$ the DL capacity rises with increased copolymer arms.

Stability is one of the critical factors in ensuring safety and efficacy of drug products. The stability of drug particles can change during manufacturing and storage. For example, formation of larger particles may lead to capillary blockade and embolism for intravenously administered nanosuspension. ${ }^{47}$ Therefore, particle size and size distribution of drug-loaded micelles need to be closely monitored during storage. In our study, the particle size and the polydispersity index were used to evaluate the stability of micelles. As shown in Figure 5D, no obvious changes were observed in mean particle size of the aqueous dispersion during 1 month stored at $4^{\circ} \mathrm{C}$ because micelle-coated PEG on the core must be stable in in vitro and in vivo conditions and desorption or displacement phenomena were effectively avoided. ${ }^{48}$ Results indicated that the micelles had satisfactory stability and could be stored for a long time. 

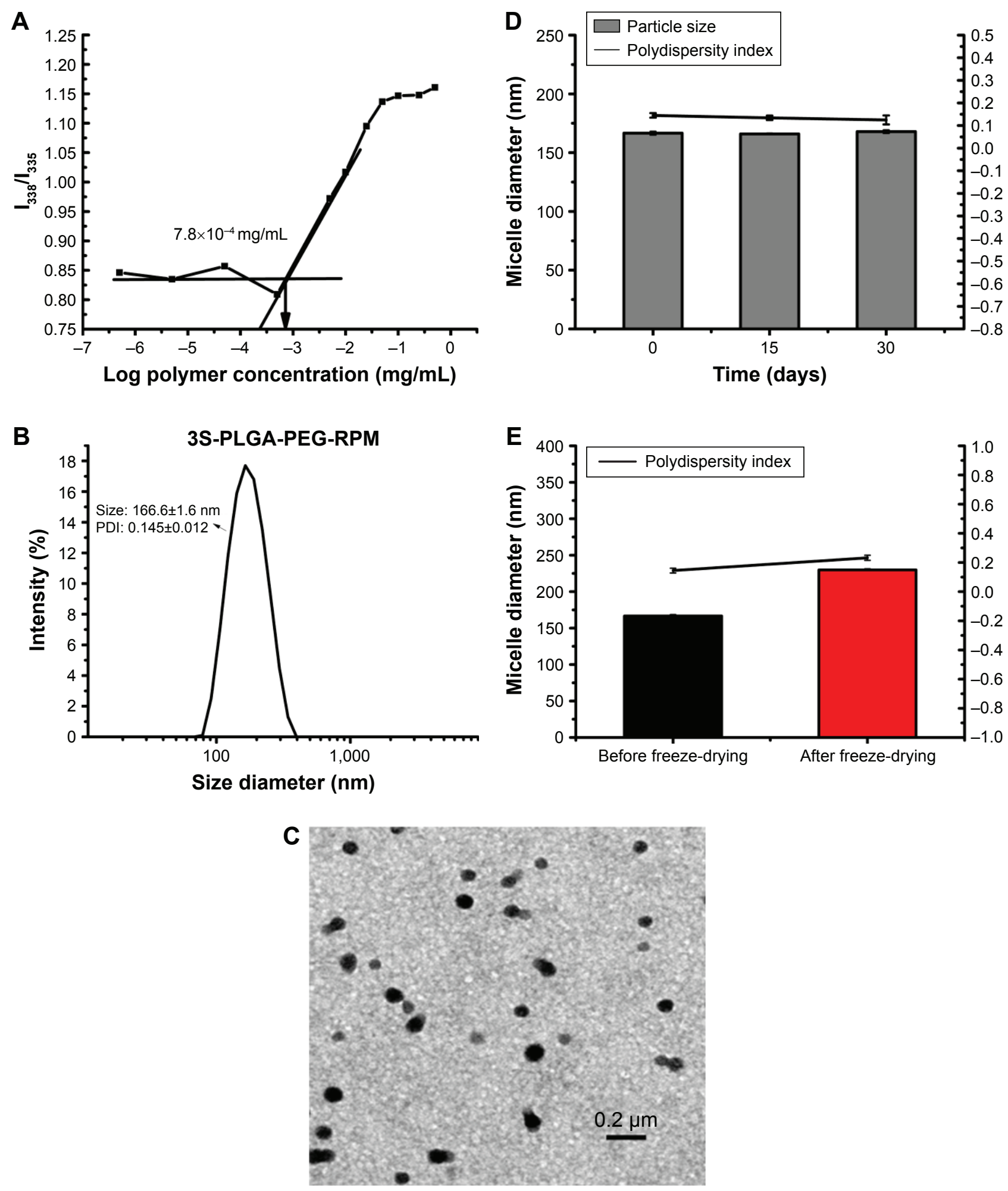

Figure 5 (A) CMC of 3S-PLGA-PEG: pyrene was used as the fluorescence probe in the measurement. With increasing polymer concentrations in aqueous solution, $I_{338} / I_{335}$ values in the excitation spectrum increased. The straight line below CMC represents the stable state of solution, the straight line above $\mathrm{CMC}$ represents the stable state of micellar solution, the point of intersection of these two lines are the Krafft point, which represents the CMC. The CMC of 3S-PLGA-PEG was $7.8 \times 10^{-4} \mathrm{mg} / \mathrm{mL}$, which suggested

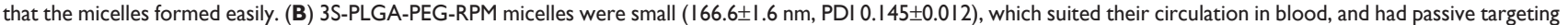
to tumor tissue. (C) TEM suggested that micelles obtained appeared similarly spherical in shape and separated from each other. The results of DTS and TEM indicated that 3S-PLGA-PEG micelles possessed ideal size and good dispersibility. (D) The stability of the micelle suspension at I month suggested that the 3S-PLGA-PEG micelles were very stable during storage in $4^{\circ} \mathrm{C}$. (E) The slight difference between before freeze-drying and after freeze-drying indicated slight sedimentation and aggregation.

Abbreviations: CMC, critical micelle concentration; 3S-PLGA, three-arm star block poly(lactic-co-glycolic acid); PEG, polyethylene glycol; RPM, rapamycin; PDI, polydispersity index; TEM, transmission electron microscopy; DTS, dynamic light scattering. 
A

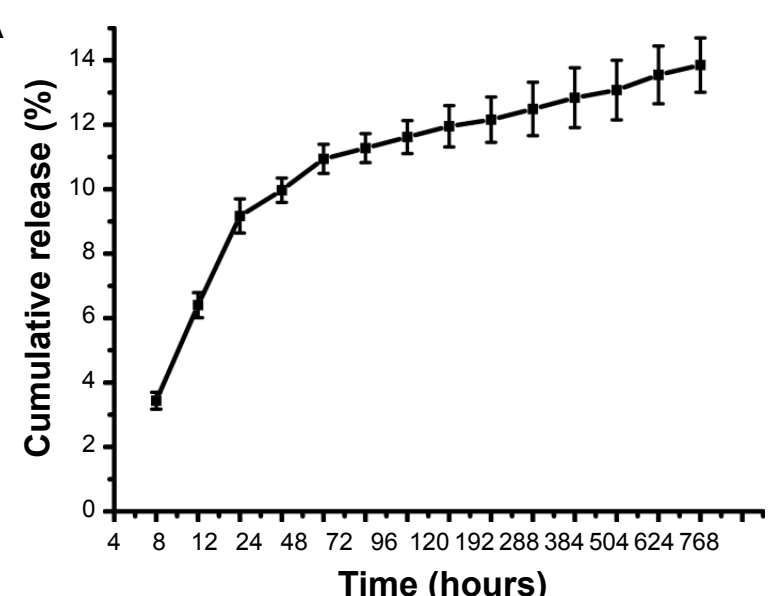

B

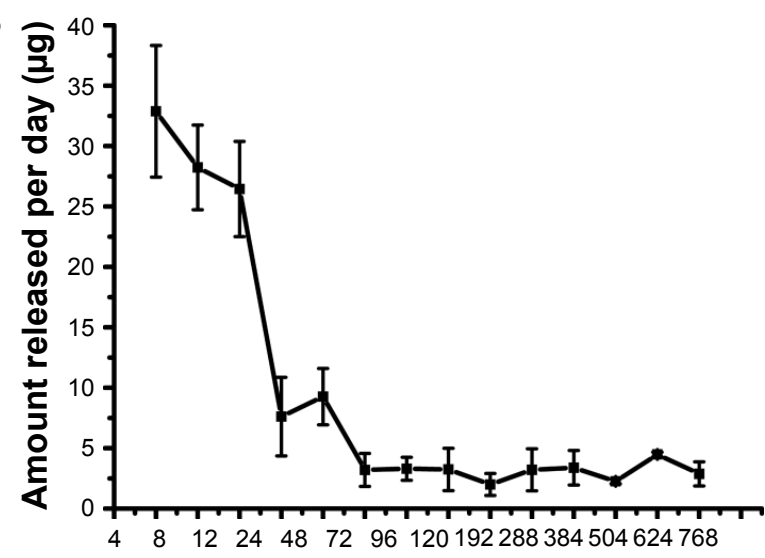

Time (hours)

Figure 6 In vitro release of RPM. (A) The drug showed sustained release: over I5\% of RPM was released in I month. (B) RPM release per day gradually reduced, however there was always drug detected in the release solution, which was still able to inhibit cell proliferation.

Abbreviation: RPM, rapamycin.

The stability of solid powder is much better than dispersion during storage due to the decrease of unstable factors. ${ }^{49,50}$ Therefore, we also made a comparison of the stability of micelles between before freeze-drying and after freeze-drying. As shown in Figure 5E, micelles after freezedrying showed a slight increase of particle size, which was induced by slight sedimentation and aggregation in the process of the freeze-drying.

\section{In vitro release}

The half-life and solubility of liposoluble drugs are significant aspects that should be taken into consideration during use. ${ }^{51,52}$ In order to improve these features, biodegradable polymers have been used frequently as drug-delivery carriers because of their nice bioavailability, better encapsulation, controlled release, and less toxic properties. ${ }^{53}$ It has been demonstrated that the existence of PEG fragments is not enough to hole the stability of micelles, but will produce increased half-life of the system in vivo. ${ }^{54}$ As shown in Figure 6A, the drug released for a long time, and there was over $15 \%$ of RPM released in 1 month. Apart from the cumulative percentage of RPM, as shown in Figure 6B, the RPM amount released per day gradually reduced, but there was always drug detected in the release solution, which can still play an inhibitory role in cell proliferation. ${ }^{55}$ Drug can be released from the delivery system in a sustained manner to prolong exposure time and increase the drug-therapy efficacy. ${ }^{56,57}$ Physically entrapped drugs were released mainly through the diffusion effect, so the driving force was reducing with the concentration of drugs in the core decreasing gradually. Therefore, both the release speed and release amount per day exhibited a trend of declining at later experimental points.

\section{Cytostatic effect in vitro}

Cytostatic assay of 3S-PLGA-PEG-RPM was also undertaken on T/G HA-VSMCs. We made a comparison of the effect among the different concentrations of RPM in micelles. As shown in Figure 7, both RPM-micelle groups and RPM-free groups were more cytotoxic after incubation for 48 and 72 hours compared to 24 hours. Also, comparison of the cytotoxic potency of the RPM-micelle and RPM-free groups showed that RPM micelles had considerably superior cytotoxic potency against T/G HA-VSMC cells at 48 and 72 hours of incubation, while they exhibited a weak form

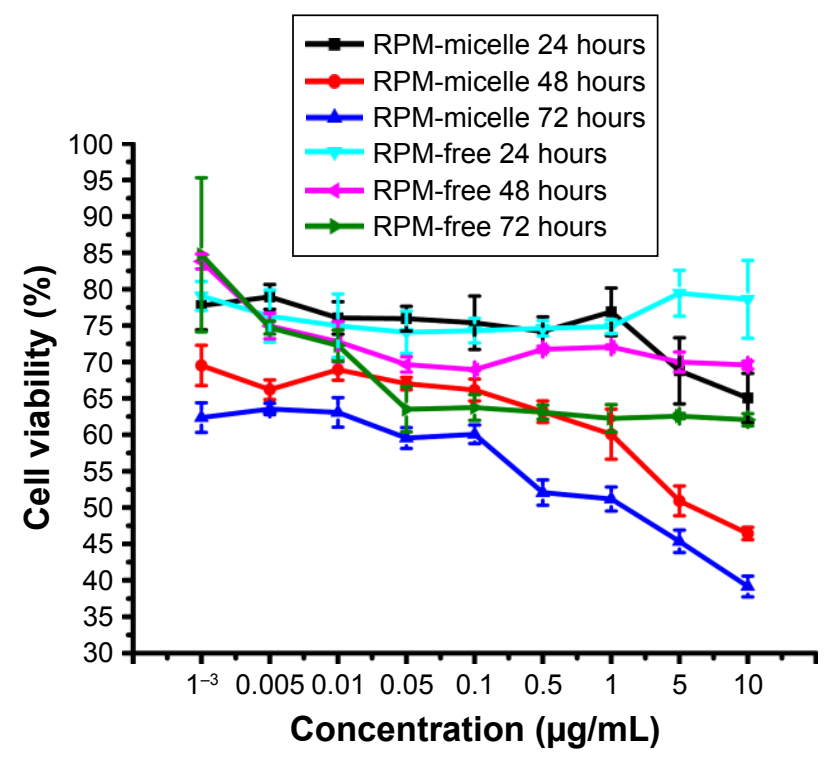

Figure 7 Cytostatic assay of 3S-PLGA-PEG-RPM.

Note: Comparison of cytotoxic potency of RPM micelles versus free RPM showed that RPM micelles had considerably superior cytotoxic potency against T/G human aortic vascular smooth-muscle cells.

Abbreviations: 3S-PLGA, three-arm star block poly(lactic-co-glycolic acid); PEG, polyethylene glycol; RPM, rapamycin. 
at 24 hours of incubation. That was probably because the free RPM concentration was higher than that released from the micelles at the early experimental point, but with time the concentration of free RPM began to decrease while RPM showed sustained release from micelles to maintain effective concentration.

Both RPM-free groups of incubation for 24, 48, and 72 hours showed a smooth trend and no obvious dosedependent phenomena among the different concentrations versus RPM-micelle groups. We speculated that the micelle system enhanced the cellular uptake of RPM through endocytosis versus the passive diffusion of free RPM through the cell membrane. The fluid-phase endocytosis mechanism may be the vital aspect that increased the cellular uptake of micelles because there was no specific affinity between the outer PEG chains of the micelles and the negatively charged membranes of the cells..$^{58-60}$

\section{Conclusion}

In this study, 3S-PLGA-PEG was synthesized by ring-opening polymerization and esterification with oxalyl chloride. The synthetic routes greatly shortened the synthetic steps and improved efficiency in the research. FT-IR, GPC, and ${ }^{1} \mathrm{H}-\mathrm{NMR}$ results proved that the $3 \mathrm{~S}-\mathrm{PLGA}-\mathrm{PEG}$ was successfully obtained. This type of copolymer had good biocompatibility and was safe to be used as the drug-delivery carrier. The RPM-loaded micelles prepared through the selfassembly method exhibited a narrow size distribution and high EE. In vitro release analysis demonstrated steady and sustained RPM release, which prolonged residence at local sites and improved the therapeutic effect. Therefore, this material prepared with this simple new method may be a promising polymeric material for drug delivery.

\section{Acknowledgments}

This work was supported by grants from the National Natural Science Foundation of China (81271706), the Tianjin Research Foundation Advanced Technology Program (13JCZDJC30700), the Technology Foundation for Selected Overseas Chinese Scholars, Ministry of Personnel of China, and the Innovative Research Team program in Peking Union Medical College.

\section{Disclosure}

The authors report no conflicts of interest in this work.

\section{References}

1. Merisko-Liversidge E, Liversidge GG, Cooper ER. Nanosizing: a formulation approach for poorly-water-soluble compounds. Eur J Pharm Sci. 2003;18(2):113-120.
2. Nicolas J. Drug-initiated synthesis of polymer prodrugs: combining simplicity and efficacy in drug delivery. Chem Mater. 2016;28(6): 1591-1606.

3. Liu D, Sue HJ, Thompson ZJ, Bates FS, Hillmyer MA. Epoxy toughening with nano-sized amphiphilic block copolymer micelles. In: Nano Science and Technology Institute, editor. Nanotechnology 2013 - Vol 1: Advanced Materials, CNTs, Particles, Films and Composites. Boca Raton (FL): CRC Press; 2013:597-600.

4. Chen F, Zhang J, He Y, Fang X, Wang Y, Chen M. Glycyrrhetinic aciddecorated and reduction-sensitive micelles to enhance the bioavailability and anti-hepatocellular carcinoma efficacy of tanshinone IIA. Biomater Sci. 2016;4(1):167-182.

5. Bastakoti BP, Liao SH, Inoue $\mathrm{M}$, et al. $\mathrm{pH}$-responsive polymeric micelles with core-shell-corona architectures as intracellular anti-cancer drug carriers. Sci Technol Adv Mater. 2013;14(4):044402.

6. Cevc G. Lipid vesicles and other colloids as drug carriers on the skin. Adv Drug Deliv Rev. 2004;56(5):675-711.

7. Kawashima Y, Niwa T, Takeuchi H, Hino T, Ito Y. Preparation of multiple unit hollow microspheres (microballoons) with acrylic resin containing tranilast and their drug release characteristics (in vitro) and floating behavior (in vivo). J Control Release. 1991;16(3):279-289.

8. Chen Y, Yang Z, Liu C, et al. Synthesis, characterization, and evaluation of paclitaxel loaded in six-arm star-shaped poly(lactic-co-glycolic acid). Int J Nanomedicine. 2013;8:4315-4326.

9. Zheng Y, Li S, Weng Z, Gao C. Hyperbranched polymers: advances from synthesis to applications. Chem Soc Rev. 2015;44(12):4091-4130.

10. Vaishya RD, Gokulgandhi M, Patel S, Minocha M, Mitra AK. Novel dexamethasone-loaded nanomicelles for the intermediate and posterior segment uveitis. AAPS PharmSciTech. 2014;15(5):1238-1251.

11. Zhang J, Li Y, Gao W, Repka MA, Wang Y, Chen M. Andrographolideloaded PLGA-PEG-PLGA micelles to improve its bioavailability and anticancer efficacy. Expert Opin Drug Deliv. 2014;11(9):1367-1380.

12. Deepagan VG, Kwon S, You DG, et al. In situ diselenide-crosslinked polymeric micelles for ROS-mediated anticancer drug delivery. Biomaterials. 2016;103:56-66.

13. Vaishya RD, Mandal A, Patel S, Mitra AK. Extended release microparticlein-gel formulation of octreotide: effect of polymer type on acylation of peptide during in vitro release. Int J Pharm. 2015;496(2):676-688.

14. Zhu KJ, Lin XZ, Yang SL. Preparation, characterization, and properties of polylactide (PLA)-poly(ethylene glycol) (PEG) copolymers: a potential drug carrier. J Appl Polym Sci. 1990;39(1):1-9.

15. Hassouna F, Raquez JM, Addiego F, Dubois P, Toniazzo V, Ruch D. New approach on the development of plasticized polylactide (PLA): grafting of poly(ethylene glycol) (PEG) via reactive extrusion. Eur Polym J. 2011;47(11):2134-2144.

16. Gao X, Wang BL, Wei XW, et al. Preparation, characterization and application of star-shaped PCL/PEG micelles for the delivery of doxorubicin in the treatment of colon cancer. Int J Nanomedicine. 2013;8:971-982.

17. Ma G, Zhang C, Zhang L, et al. Doxorubicin-loaded micelles based on multiarm star-shaped PLGA-PEG block copolymers: influence of arm numbers on drug delivery. J Mater Sci Mater Med. 2016;27(1):17.

18. Locatelli E, Franchini MC. Biodegradable PLGA-b-PEG polymeric nanoparticles: synthesis, properties, and nanomedical applications as drug delivery system. J Nanopart Res. 2012;14(12):1-17.

19. Gref R, Minamitake Y, Peracchia MT, Trubetskoy V, Torchilin V, Langer R. Biodegradable long-circulating polymeric nanospheres. Science. 1994;263(5153):1600-1603.

20. Scalley-Kim M, Minard P, Baker D. Low free energy cost of very long loop insertions in proteins. Protein Sci. 2003;12(2):197-206.

21. Farokhzad OC, Cheng J, Teply BA, et al. Targeted nanoparticle-aptamer bioconjugates for cancer chemotherapy in vivo. Proc Natl Acad Sci U S A. 2006;103(16):6315-6320.

22. Cheng J, Teply BA, Sherifi I, et al. Formulation of functionalized PLGAPEG nanoparticles for in vivo targeted drug delivery. Biomaterials. 2007;28(5):869-876.

23. Kwon J, Kim J, Park S, Khang G, Kang PM, Lee D. Inflammationresponsive antioxidant nanoparticles based on a polymeric prodrug of vanillin. Biomacromolecules. 2013;14(5):1618-1626. 
24. Yang GC, Chen ZX, Zhang ZJ, Qiu XL. Novel synthesis of monoethers of hydroquinone and resorcinol on soluble polymer-supports. Synth Commun. 2002;32(23):3637-3642.

25. Jiang XY, Li YJ, Lu GL, Huang XY. A novel poly (N-vinylcaprolactam)based well-defined amphiphilic graft copolymer synthesized by successive RAFT and ATRP. Polym Chem. 2013;4(5):1402-1411.

26. Bates CM, Chang AB, Schulze MW, Momcilovic N, Jones SC, Grubbs RH. Brush polymer ion gels. J Polym Sci B Polym Phys. 2016;54(2): 292-300.

27. Arkas M, Papavasiliou A. Effects of hydrogen-bonding on the liquid crystalline properties of dendritic polymers. In: Thakur VK, Kessler LR, editors. Liquid Crystalline Polymers. Heidelberg: Springer; 2016: 173-194.

28. Fan X, Zhao Y, Xu W, Li L. Linear-dendritic block copolymer for drug and gene delivery. Mater Sci Eng C Mater Biol Appl. 2016;62: 943-959.

29. Dechy-Cabaret O, Martin-Vaca B, Bourissou D. Controlled ring-opening polymerization of lactide and glycolide. Chem Rev. 2004;104(12): 6147-6176.

30. Mei L, Jiang Y, Feng SS. Star-shaped block polymers as a molecular biomaterial for nanomedicine development. Nanomedicine (Lond). 2014;9(1):9-12.

31. Agrahari V, Agrahari V, Hung WT, Christenson LK, Mitra AK. Composite nanoformulation therapeutics for long-term ocular delivery of macromolecules. Mol Pharm. 2016;13(9):2912-2922.

32. Dong Y, Feng SS. Methoxy poly(ethylene glycol)-poly(lactide) (MPEG-PLA) nanoparticles for controlled delivery of anticancer drugs. Biomaterials. 2004;25(14):2843-2849.

33. Lee SJ, Han BR, Park SY, Han DK, Kim SC. Sol-gel transition behavior of biodegradable three-arm and four-arm star-shaped PLGAPEG block copolymer aqueous solution. J Polym Sci A Polym Chem. 2006;44(2):888-899.

34. Lu DD, Yuan JC, Li HG, Lei ZQ. Synthesis and characterization of a series of biodegradable and biocompatible PEG-supported poly(lacticran-glycolic acid) amphiphilic barbell-like copolymers. J Polym Sci A Polym Chem. 2008;46(11):3802-3812.

35. Weber K, Bloom O, Quraishi S, Overby MC, Levine M, Chahine N. Serum levels of the pro-inflammatory cytokines IL-6 and TNF- $\alpha$ vary based on diagnoses in individuals with low back pain. Global Spine J. 2016;6(S1):WST008.

36. Mirza S, Hossain M, Mathews C, et al. Type 2-diabetes is associated with elevated levels of TNF- $\alpha$, IL-6 and adiponectin and low levels of leptin in a population of Mexican Americans: a cross-sectional study. Cytokine. 2012;57(1):136-142.

37. Kalyanasundaram K, Thomas JK. Environmental effects on vibronic band intensities in pyrene monomer fluorescence and their application in studies of micellar systems. J Am Chem Soc. 1977;99(7):2039-2044.

38. Zhang K, Tang X, Zhang J, et al. PEG-PLGA copolymers: their structure and structure-influenced drug delivery applications. J Control Release. 2014;183:77-86.

39. Win KY, Feng SS. Effects of particle size and surface coating on cellular uptake of polymeric nanoparticles for oral delivery of anticancer drugs. Biomaterials. 2005;26(15):2713-2722.

40. Foged C, Brodin B, Frokjaer S, Sundblad A. Particle size and surface charge affect particle uptake by human dendritic cells in an in vitro model. Int J Pharm. 2005;298(2):315-322.

41. Lee KD, Nir S, Papahadjopoulos D. Quantitative analysis of liposomecell interactions in vitro: rate constants of binding and endocytosis with suspension and adherent $\mathrm{J} 774$ cells and human monocytes. Biochemistry. 1993;32(3):889-899.
42. De Jong WH, Hagens WI, Krystek P, Burger MC, Sips AJ, Geertsma RE. Particle size-dependent organ distribution of gold nanoparticles after intravenous administration. Biomaterials. 2008;29(12):1912-1919.

43. He C, Hu Y, Yin L, Tang C, Yin C. Effects of particle size and surface charge on cellular uptake and biodistribution of polymeric nanoparticles. Biomaterials. 2010;31(13):3657-3666.

44. Zhang JZ, Jiang W, Zhao XW, Wang YD. Preparation and characterization of polymeric micelles from poly (D,L-lactide) and methoxypolyethylene glycol block copolymers as potential drug carriers. Tsinghua Sci Technol. 2007;12(4):493-496.

45. Allen C, Maysinger D, Eisenberg A. Nano-engineering block copolymer aggregates for drug delivery. Colloids Surf B Biointerfaces. 1999; 16(1):3-27.

46. Kojima C, Kono K, Maruyama K, Takagishi T. Synthesis of polyamidoamine dendrimers having poly(ethylene glycol) grafts and their ability to encapsulate anticancer drugs. Bioconjug Chem. 2000;11(6):910-917.

47. Patravale VB, Kulkarni RM. Nanosuspensions: a promising drug delivery strategy. J Pharm Pharmacol. 2004;56(7):827-840.

48. Bazile D, Prud'homme C, Bassoullet MT, Marlard M, Spenlehauer G, Veillard M. Stealth Me.PEG-PLA nanoparticles avoid uptake by the mononuclear phagocytes system. J Pharm Sci. 1995;84(4):493-498.

49. Van Eerdenbrugh B, Van den Mooter G, Augustijns P. Top-down production of drug nanocrystals: nanosuspension stabilization, miniaturization and transformation into solid products. Int J Pharm. 2008; 364(1):64-75.

50. Abdelwahed W, Degobert G, Stainmesse S, Fessi H. Freeze-drying of nanoparticles: formulation, process and storage considerations. $A d v$ Drug Deliv Rev. 2006;58(15):1688-1713.

51. Albengres E, Le Louet H, Tillement JP. Immunosuppressive drugs and pregnancy: experimental and clinical data. Transplant Proc. 1997;29(5): 2461-2466.

52. Zhou H, Wan J, Wu L, et al. A new strategy for enhancing the oral bioavailability of drugs with poor water-solubility and low liposolubility based on phospholipid complex and supersaturated SEDDS. PloS One. 2013;8(12):e84530.

53. Kumari A, Yadav SK, Yadav SC. Biodegradable polymeric nanoparticles based drug delivery systems. Colloids Surf B Biointerfaces. 2010; 75(1):1-18.

54. Mosqueira VC, Legrand P, Morgat JL, et al. Biodistribution of longcirculating PEG-grafted nanocapsules in mice: effects of PEG chain length and density. Pharm Res. 2001;18(10):1411-1419.

55. Ma KL, Ruan XZ, Powis SH, Moorhead JF, Varghese Z. Anti-atherosclerotic effects of sirolimus on human vascular smooth muscle cells. Am J Physiol Heart Circ Physiol. 2007;292(6):H2721-H2728.

56. Bharali DJ, Mousa SA. Emerging nanomedicines for early cancer detection and improved treatment: current perspective and future promise. Pharmacol Ther. 2010;128(2):324-335.

57. Holgado MA, Arias JL, Cózar MJ, Alvarez-Fuentes J, Gañán-Calvo AM, Fernández-Arévalo M. Synthesis of lidocaine-loaded PLGA microparticles by flow focusing: effects on drug loading and release properties. Int J Pharm. 2008;358(1-2):27-35.

58. Yoo HS, Park TG. Biodegradable polymeric micelles composed of doxorubicin conjugated PLGA-PEG block copolymer. J Control Release. 2001;70(1):63-70.

59. Zhang Y, Kohler N, Zhang M. Surface modification of superparamagnetic magnetite nanoparticles and their intracellular uptake. Biomaterials. 2002;23(7):1553-1561.

60. Chen YC, Lo CL, Lin YF, et al. Rapamycin encapsulated in dualresponsive micelles for cancer therapy. Biomaterials. 2013;34(4): 1115-1127. 
International Journal of Nanomedicine

Dovepress

\section{Publish your work in this journal}

The International Journal of Nanomedicine is an international, peerreviewed journal focusing on the application of nanotechnology in diagnostics, therapeutics, and drug delivery systems throughou the biomedical field. This journal is indexed on PubMed Central, MedLine, CAS, SciSearch ${ }^{\circledR}$, Current Contents ${ }^{\circledR} /$ Clinical Medicine,
Journal Citation Reports/Science Edition, EMBase, Scopus and the Elsevier Bibliographic databases. The manuscript management system is completely online and includes a very quick and fair peer-review system, which is all easy to use. Visit http://www.dovepress.com/ testimonials.php to read real quotes from published authors.

Submit your manuscript here: http://www.dovepress.com/international-journal-of-nanomedicine-journal 